\title{
ESTUDO DE TURFA E CARVÃO ATIVADO COMO ADSORVENTES PARA REMOÇÃO DE HIDROCARBONETOS DE MEIO AQUOSO
}

\section{PEAT AND ACTIVATED CARBON AS ADSORBENT FOR AQUEOUS MEDIUM OIL REMOVAL}

\author{
Patricia Darolt de Costa ${ }^{1}$ \\ Thamires Custódio Jeremias ${ }^{1}$ \\ Carlyle Torres Bezerra Menezes ${ }^{1}$
}

\section{RESUMO}

Atualmente um dos maiores desafios técnico-científicos no que diz respeito às questões ambientais é quanto aos métodos mais seguros de recuperação ambiental de áreas contaminadas por derrames de petróleo, sobretudo em ambientes marinho-costeiros. Com o aumento de consumo do petróleo e seus derivados, bem como a crescente exploração pelo Brasil, houve um crescimento no tráfego dos navios que transportam este combustível, proporcionando um risco maior de acidentes marítimos com derrame do mesmo, podendo provocar a contaminação do oceano, dos ecossistemas costeiros e da fauna e flora. Neste contexto, episódios de vazamentos de hidrocarbonetos mostram a necessidade de estudos de remediação/tratamento dos sítios contaminados e no desenvolvimento de novas alternativas tecnológicas. A técnica aplicada neste trabalho para o estudo de remoção de hidrocarbonetos foi a adsorção. Foram utilizados dois tipos de adsorventes, a turfa decomposta e um carvão ativado produzido a partir da casca do arroz. Os resultados obtidos nos ensaios de adsorção apontam para um bom potencial de uso dos adsorventes utilizados na remoção de hidrocarbonetos.

PALAVRAS-CHAVE: Adsorção; Hidrocarbonetos; Ambientes costeiros

\begin{abstract}
Nowadays, one of the largest technical and scientific challenges with regard to environmental issues is about the safest methods of environmental recovery of areas contaminated by oil spills, especially in coastal marine environments. With the increase in oil consumption and its derivatives, as well as the increasing exploitation by Brazil, there was an increasing traffic of ships carrying this fuel, providing a greater risk of maritime accidents, causing contamination of the ocean and coastal areas and fauna and flora ecosystems. In this context, episodes of hydrocarbon leaks show the need for remediation/treatment studies of contaminated sites and the development of new alternative technologies. The method applied in this work for the study of oil spill was the adsorption technique. Two types of adsorbents were used, decomposed peat and an activated carbon produced from rice hulls. Results obtained from adsorption experiments indicate good potential for the use of adsorbents for hydrocarbon removal.
\end{abstract}

KEYWORDS: Adsorption; Hydrocarbons; Coastal environments

\section{INTRODUÇÃO}

\footnotetext{
${ }^{1}$ Universidade do Extremo Sul Catarinense - UNESC _ PPGCA (Programa de Pós Graduação em Ciências Ambientais).
} 
Um dos maiores desafios técnico-científicos no que diz respeito às questões ambientais é quanto aos métodos mais seguros de recuperação ambiental de áreas contaminadas por derrames de petróleo e seus derivados.

Essa preocupação tem aumentado nos últimos anos, sobretudo devido à intensidade e a frequência com que esses acidentes têm ocorrido. No Brasil, a perspectiva da pesquisa e produção de petróleo em profundidades cada vez maiores, tais como a denominada de Camada Pré-Sal, torna mais urgente o desenvolvimento de pesquisas e novas tecnologias de prevenção e tratamento de sítios contaminados.

Com o aumento de consumo do petróleo pelos países industrializados, houve um crescimento no tráfego dos navios que transportam este combustível, proporcionando um risco maior de acidentes marítimos com derrame do mesmo, provocando a contaminação dos ecossistemas costeiros e da biota (BÍCEGO, 2008). Vazamentos de hidrocarbonetos podem acontecer inadvertidamente durante vários processos tais como transporte marítimo de cargas, extração de petróleo, refino, distribuição, e mesmo durante a comercialização final (MENIZE, et al. 1992 apud ROSIN, 2007).

Os impactos sobre os organismos podem ser físicos quando os mesmos são recobertos pelo produto derramado podendo levar à morte dos mesmos por asfixia, e/ou tóxicos quando acumulam os hidrocarbonetos depositados no sedimento. Os efeitos tóxicos podem dizimar culturas inteiras de recursos pesqueiros (LOPES; MILANELLI; POFFO, 2007). Isso porque, o petróleo apresenta um grande número de compostos orgânicos mutagênicos e/ou carcinogênicos, além da fase inorgânica. Consiste basicamente em compostos de apenas dois elementos que, no entanto, formam grande variedade de complexas estruturas moleculares. O hidrogênio e o carbono são os mais importantes e prevalecentes elementos, compondo $98 \%$ de certos óleos crus e $100 \%$ de muitos produtos refinados (EPA, 1999).

Neste contexto, este trabalho consistiu no estudo comparativo acerca de técnicas de adsorção para remediação de ambientes marinho-costeiros contaminados por hidrocarbonetos oriundos de derrames de petróleo e derivados. Esta técnica é considerada superior a outras técnicas, como de precipitação, troca iônica, coagulação e osmose reversa, devido à possibilidade de reutilização da água após o processo, simplicidade, facilidade de operação e insensibilidade aos compostos tóxicos (RAFATULLAH et al, 2010). 
Para o estudo, foi selecionado o composto benzo[a]pireno, hidrocarboneto com alto grau de toxicidade, para avaliação da eficiência do processo de adsorção, com o uso de dois tipos de adsorventes, a turfa classificada como decomposta de origem litorânea e um carvão ativado produzido a partir da casca do arroz. A turfa e a casca de arroz foram selecionadas para o estudo devido principalmente a sua elevada quantidade na região Sul catarinense.

\section{METODOLOGIA}

Os procedimentos experimentais compreenderam etapas de caracterização dos materiais e ensaios de adsorção. A caracterização das substâncias adsorventes foi realizada por Análise Granulométrica e Espectroscopia no Infravermelho por Transformada de Fourier (FTIR). O ensaio de FTIR foi realizado para os materiais, na região do infravermelho, em pastilhas de $\mathrm{KBr}$, em um equipamento Shimadzu (IR Prestige-21), na faixa de 400 a $4000 \mathrm{~cm}^{-1}$, em intervalos de $2 \mathrm{~cm}^{-1}$. As análises foram realizadas antes e após os ensaios de tratamento em colunas de adsorção.

A concentração padrão do benzo[a]pireno determinada para os ensaios foi de 50 $\mu \mathrm{g}$ em um volume de $25 \mathrm{~mL}$.

A preparação dos adsorventes foi realizada em duas etapas: carbonização e ativação com uso de reagentes. Essas condições foram replicadas para os tipos de adsorventes selecionados.

A casca do arroz foi submetida ao processo de ativação com ácido clorídrico na concentração de $1 \mathrm{~mol} / \mathrm{L}$, em chapa de aquecimento durante 1 hora a $300^{\circ} \mathrm{C}$. Em seguida, a casca do arroz foi lavada com água deionizada para remoção do excesso de ácido e posteriormente disposto em estufa durante 4 horas e a $100^{\circ} \mathrm{C}$. Posteriormente, o adsorvente foi submetido ao tratamento térmico em temperatura de $600^{\circ} \mathrm{C}$ durante 6 horas. $\mathrm{O}$ carvão ativado obtido foi peneirado e selecionado o material abaixo de $74 \mu \mathrm{m}$. Foi selecionado o material abaixo deste tamanho, pois, quanto menor o tamanho das partículas, maior será a superfície específica e, consequentemente, mais eficiente será a adsorção.

Os ensaios de adsorção foram realizados em colunas em uma proporção de $2 \mathrm{~g}$ de cada um dos adsorventes para $25 \mathrm{~mL}$ de solução de benzo[a]pireno. Antes e após os 
ensaios de adsorção, as análises para a avaliação dos percentuais de remoção do benzo[a]pireno foram realizadas por meio do método EPA $8270 \mathrm{D}$, e o equipamento utilizado foi um cromatógrafo gasoso para análise de compostos orgânicos, do tipo CG/MS ion trap, modelo 240MS (G3931A).

\section{RESULTADOS E DISCUSSÕES}

É possível afirmar, conforme os resultados do espectro FTIR, que as substâncias presentes na turfa são compostas por elevado conteúdo em grupamentos oxigenados, tais como carboxílicos e fenólicos, sendo que estes possuem grande reatividade e atuam diretamente na troca iônica, na quelação e na adsorção.

O espectro de FTIR da Turfa Decomposta (TD) está ilustrado na Figura 01.

Figura 01: FTIR da Turfa Decomposta (TD)

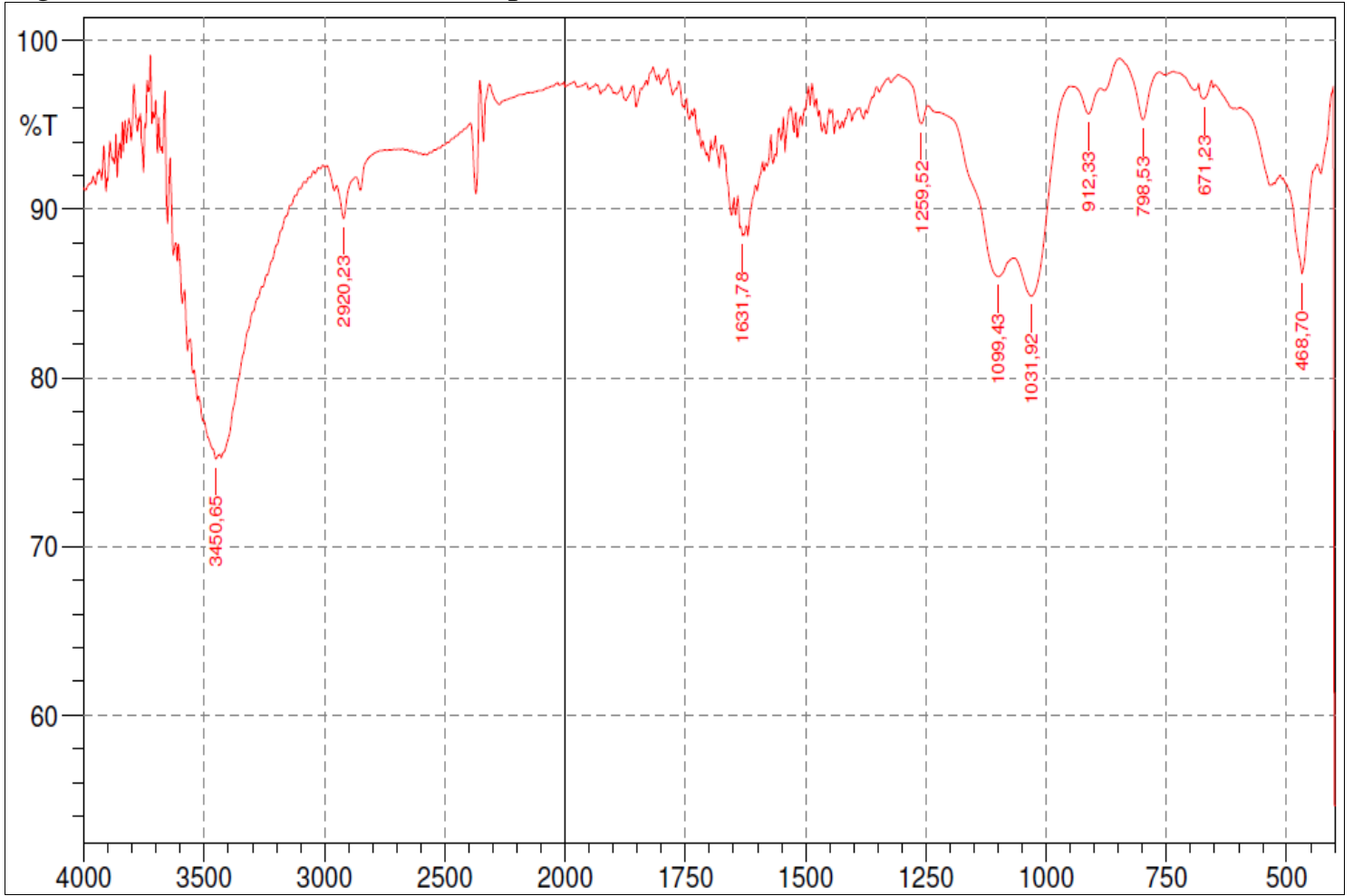

Fonte: Gráfico gerado pela Espectroscopia no Infravermelho por Transformada de Fourier.

O espectro da turfa demonstrou a presença de bandas em torno de $3440 \mathrm{~cm}^{-1}$ referentes ao estiramento da ligação -OH. Foi identificada a presença de duas bandas em torno de 2920 e $2850 \mathrm{~cm}^{-1}$ o que sugere o estiramento assimétrico de $\mathrm{C}-\mathrm{H}$ alifático. As 
bandas em torno de 1780 e $1720 \mathrm{~cm}^{-1}$ indicam a presença de $\mathrm{C}=\mathrm{O}$ referente aos grupos funcionais carbonilas. Foi identificada também uma banda em torno de $1650 \mathrm{~cm}^{-1}$ provavelmente relacionada às vibrações de $\mathrm{C}=\mathrm{C}$ de aromáticos e agrupamentos de $\mathrm{COO}^{-}$.

No que se refere à casca de arroz, percebeu-se conforme os resultados demonstrados no FTIR (ilustrado na Figura 02) que esta é composta por macromoléculas e matrizes relacionadas ao estiramento $-\mathrm{OH}$ e $-\mathrm{CH}$. Destaca-se uma banda em torno de $800 \mathrm{~cm}^{-1}$ referente ao estiramento simétrico das ligações do silício.

Figura 02: FTIR da casca de arroz

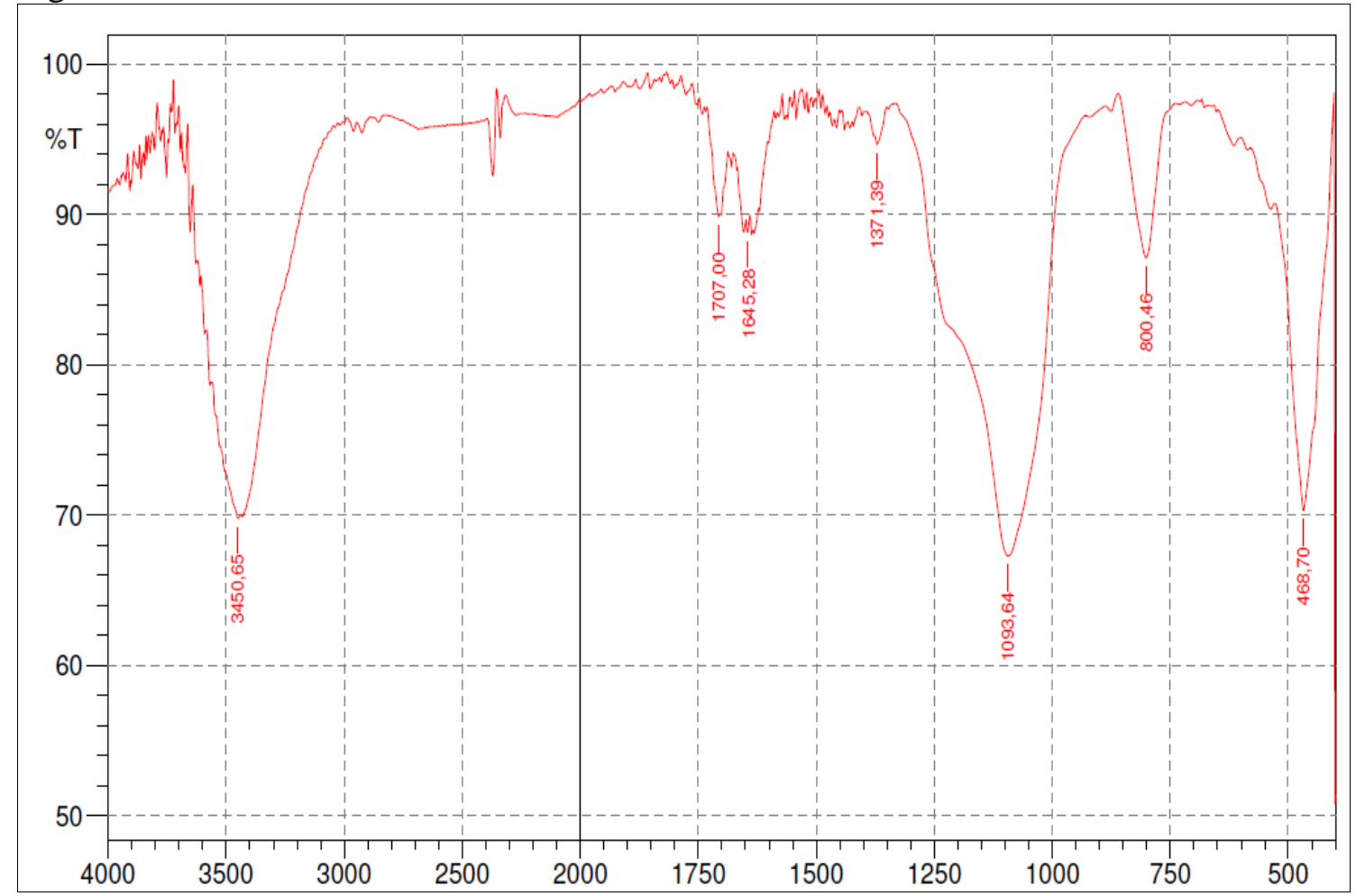

Fonte: Gráfico gerado pela Espectroscopia no Infravermelho por Transformada de Fourier.

O espectro de FTIR do adsorvente produzido a partir da casca de arroz mostra a presença de bandas em torno de $3440 \mathrm{~cm}^{-1}$ referentes ao estiramento da ligação - $\mathrm{OH}$, comuns em matrizes celulósicas. Após o tratamento térmico da casca de arroz percebese a diminuição quase total das bandas referentes à ligação $-\mathrm{OH}$ e $-\mathrm{CH}$ e aumento de intensidade da banda de $1090 \mathrm{~cm}^{-1}$ referente às ligações assimétricas das ligações do silício. 
No que se refere à eficiência na remoção do benzo(a)pireno, ambas as amostras de adsorventes apresentaram percentuais elevados, sendo que nas condições dos ensaios, a concentração final do contaminante foi de 22,50 $\mu \mathrm{g}$ (microgramas) para o tratamento com o carvão ativado produzido com a casca de arroz, e de 28,50 $\mu \mathrm{g}$ (microgramas) com a turfa decomposta. Esses valores correspondem à remoção de $43 \%$ com o uso da turfa, e 55\% com o adsorvente produzido com a casca de arroz.

Os resultados obtidos apontam para um bom potencial de uso dos adsorventes utilizados na remoção de contaminantes oriundos de derrames de petróleo e derivados em regiões litorâneas. Dessa forma, a pesquisa e técnicas de adsorção propostas nesse trabalho possibilitaram realizar um estudo comparativo dos adsorventes selecionados, que poderão contribuir de forma significativa para a mitigação dos impactos causados por derrames ou vazamentos de hidrocarbonetos. Tais impactos contribuem também para um aumento significativo no número de problemas socioambientais, afetando negativamente tanto a produção pesqueira, quanto as atividades de turismo e lazer da região litorânea.

Estudos mais aprofundados são necessários visando um maior conhecimento e interpretação dos mecanismos de adsorção responsáveis pela remoção do benzo(a)pireno, com vistas a subsidiar trabalhos futuros para a mitigação de impactos ambientais em ambientes marinho-costeiros, tais como acidentes com embarcações ou plataformas de petróleo.

Em função de suas características e interações entre o meio biótico e abiótico, os ecossistemas marinho-costeiros são extremamente sensíveis e de difícil recuperação, conforme pode ser comprovado pelo histórico dos desastres ambientais e soluções de recuperação aplicadas. Nesse contexto, considerando a necessidade de uso de materiais e técnicas adaptadas às diversas realidades regionais e recursos locais disponíveis, os materiais adsorventes pesquisados neste trabalho constituem-se em importantes alternativas tecnológicas a serem estudadas e aperfeiçoadas.

\section{CONCLUSÃO}

Considerando que um dos adsorventes, a casca de arroz corresponde a um resíduo agrícola existente em grandes quantidades em várias regiões no Brasil, inclusive 
próximo às regiões costeiras, ele constitui-se em uma importante alternativa para a remediação de áreas contaminadas, e a remoção de contaminantes compostos por hidrocarbonetos oriundos do petróleo, com baixo custo e mecanismos de adsorção comprovados. A turfa decomposta apresentou resultados promissores em termos de adsorção, porém, em função da sua composição e possíveis efeitos ambientais devido a sua composição e formas de extração, ainda são necessários maiores estudos com vistas a sua viabilidade técnica, econômica e ambiental.

Estudos mais aprofundados são necessários visando um maior conhecimento e interpretação dos mecanismos de adsorção responsáveis pela remoção do benzo[a]pireno, que poderão subsidiar trabalhos futuros com a mitigação de impactos ambientais decorrentes que possam ocorrer em ambientes marinho-costeiros extremamente sensíveis, tais como acidentes com embarcações ou plataformas de petróleo.

\section{Agradecimentos}

Os autores agradecem o apoio obtido por meio do financiamento de bolsas de pesquisa no âmbito do programa PIBIC/UNESC.

\section{REFERÊNCIAS}

BÍCEGO, M. C. et al. Poluição por petróleo. In: BAPTISTA NETO, J. A.; KERSANACH, M. W.; PATCHINEELAN. Poluição Marinha. Rio de Janeiro: Interciência, 2008. 440p.

EPA (UNITED STATES ENVIRONMENTAL PROTECTION AGENCY) 1999. Understanding oil spills and oil spill response. Disponível em:

<http://www.epa.gov/oilspill/pdfbook.htm>. Acesso em 06 nov 2014.

LOPES, C. F.; MILANELli, J. C. C; POFFO, I. R. F. Ambientes costeiros contaminados por óleo: procedimentos de limpeza - manual de orientação. São Paulo: Secretaria de Estado do Meio Ambiente, 2007.120 p.

RAFATULLAH, M. et al. Adsorption of methylene blue on low-cost adsorbents: a review, Journal of Hazardous Materials. n. 177, 2010, p. 70-80.

ROSIN, A. P. Comparação da eficiência dos métodos de fenton e ozonização no tratamento de sedimento estuarino contaminado por petróleo cru. 2007. 103f. Dissertação (Mestrado em Ciência e Tecnologia ambiental. Área de concentração: Tecnologia e Gestão Ambiental. Universidade do Vale do Itajaí, Itajaí. 